\title{
PRILOG ISTARSKOJ ARHIVSKOJ GLAGOLJSKOJ BAŠTINI (GLAGOLJICA U DRŽAVNOM ARHIVU U PAZINU I U ŽUPNOM UREDU U BERMU)*
}

\author{
Mirela MRAK \\ Maja MILOVAN \\ Državni arhiv u Pazinu \\ Vladimira Nazora 3, Pazin
}

\author{
UDK 003.349.1(497.571):930.253(497.571Pazin) \\ 003.349.1(497.571):2-774(497.571Beram)
}

Izlaganje sa znanstvenog skupa

\begin{abstract}
Budući da je o iznimnoj važnosti i utjecaju same glagoljice i glagoljaške riječi na cjelokupnu hrvatsku kulturu i pismenost napisan velik broj radova onih stručnjaka koji navedenu tematiku vrlo dobro poznaju, ovim radom autorice neće ulaziti u dubinu same teorijske problematike glagoljice, već će pokušati dati pregled koji bi bio svojevrsna smjernica i vodič za buduća istraživanja arhivskoga glagoljskog gradiva pohranjenoga u Državnom arhivu u Pazinu i u arhivu Župnoga ureda u Bermu.
\end{abstract}

Ključne riječi: Državni arhiv u Pazinu, arhivsko glagoljsko gradivo, Župni ured Beram.

Keywords: $\quad$ State Archives in Pazin, archival glagolitic records, Parish office in Beram.

Parole chiave: Archivio di Stato di Pisino, materiale archivistico in glagolitico, Ufficio parrocchiale di Beram (Vermo).

I.

\section{GLAGOLJICA U DRŽAVNOM ARHIVU U PAZINU}

U arhivskom gradivu Državnoga arhiva u Pazinu dosad su evidentirana ukupno 24 arhivska dokumenta na glagoljici (što uključuje i zapise u dvjema matičnim knjigama) u ukupno sedam različitih arhivskih fondova i zbirki. Većinu je tih isprava transliterirao i objavio Dražen Vlahov u knjizi Zbirka glagoljskih isprava iz Istre. ${ }^{1}$

Najviše je dokumenta na glagoljici (njih sedam) evidentirano u arhivskom fondu HRDAPA-8 Bilježnici Poreča. ${ }^{2}$ Svi su ti dokumenti oporučnoga karaktera i nastali su u rasponu od 1629. do 1707. godine, a riječ je o sljedećim dokumentima:

\footnotetext{
* $\quad$ Rad je u ponešto skraćenu obliku pod naslovom »O istarskoj arhivskoj glagoljskoj baštini« iznijet na međunarodnoj arhivističkoj konferenciji Stanje i perspektive arhivske glagoljske baštine, Pazin - Rijeka, 28. i 29. svibnja 2015., koju je organizirao Državni arhiv u Pazinu, u suradnji s Hrvatskim državnim arhivom (Zagreb), Državnim arhivom u Rijeci i ICARUS-om (International Center for Archival Research). Dražen VLAHOV, Zbirka glagoljskih isprava iz Istre, Posebna izdanja sv. 19, Glagoljski rukopisi sv. 8, Državni arhiv u Pazinu, Pazin, 2010.

2 Državni arhiv u Pazinu, HR-DAPA-8 Bilježnici Poreča, 1433/1820 [1821/1841].
} 
1. Oporuka Antona Jurkovića iz Fuškulina (29. rujna 1629.),

bilježnik: Marc Antonio Raguzzi, kut. $4^{3}$

2. Oporuka Mare, žene Stipe Starića (12. lipnja 1656.),

bilježnik: Antonio Pavano, kut. $11^{4}$

3. Dodatak oporuci Mate Litara (13. svibnja 1661.),

bilježnik: Antonio Pavano, kut. $11^{5}$

4. Oporuka Stipe Blaževića iz Vabrige (30. travnja 1673.),

bilježnik: Antonio Pavano, kut. $11^{6}$

5. Oporuka Jeke, žene Ive Pajica iz Vabrige (15. srpnja 1677.),

bilježnik: Marc'Antonio Corsino, kut. $16^{7}$

6. Preslik oporuke pre Martina Ritoše, kurata Nove Vasi Porečke (14. srpnja 1701.),

bilježnik: Christoforo Albertini, kut. $32^{8}$

7. Oporuka Frane Dunatovića iz Punta na Krku (28. siječnja 1707.),

bilježnik: Giacomo Paglietti, kut. 53. ${ }^{9}$

Po količini glagoljskih zapisa nakon porečkih bilježnika slijedi fond HR-DAPA-4 Općina Novigrad ${ }^{10} \mathrm{~s}$ pet glagoljskih isprava. Sačuvano je glagoljsko gradivo također oporučnoga karaktera i nastalo je u razdoblju od 1520. do 1596. godine:

1. Oporuka Radića koju je zapisao domin Brnadin, kapelan na Kružvici (1520.),

Novigradska kancelarija, knj. $6^{11}$

2. Oporuka Jelene, žene pok. Domjana Perlata iz Brtonigle (18. lipnja 1534.),

Novigradska kancelarija, knj. 10 12

3. Oporuka Bartola Dužića iz Brtonigle (5. listopada 1564.),

Novigradska kancelarija, knj. $190^{13}$

4. Oporuka Katarine, žene Gašpara Valko (26. travnja 1566.),

VLAHOV, Zbirka glagoljskih isprava iz Istre, str. 208, 209, 332 i 333.

Isto, str. 218, 219 i 334.

Isto, str. 219, 220 i 335.

Isto, str. 220, 221, 222, 336, 337 i 338.

Isto, str. 223, 224, 339 i 340.

Isto, str. 224.

Isto, str. 225.

Državni arhiv u Pazinu, HR-DAPA-4 Općina Novigrad, 1471-1797.

VLAHOV, Zbirka glagoljskih isprava iz Istre, str. 320.

Isto, str. 107, 108 i 321.

Isto, str. 111, 112, 324 i 325. 
Novigradska kancelarija, knj. $190^{14}$

5. Potvrda fra Benedita iz Novigrada o podmirenju samostanskoga duga (28. veljače 1596.),

Novigradska kancelarija, f. 7 a (alegat). ${ }^{15}$

Slijedi fond HR-DAPA-811 Podestat općina Labin i Plomin ${ }^{16} \mathrm{~s}$ četiri glagoljske isprave. Sačuvani se glagoljski dokumenti odnose na miraze nastale u rasponu od 1575. do 1615. godine. Glagoljsko je gradivo ovom fondu pripojeno nakon što je bilo izdvojeno iz fonda HR-DAPA-2 Općina Labin. Riječ je o sljedećim ispravama:

1. Popis miraza Fume Golub iz Brseča, (30. listopada 1575.) ${ }^{17}$

2. Popis miraza Orse, kćeri Martina Velčića (23. svibnja 1588.) ${ }^{18}$

3. Izjava fra Mihaela Skomeržića (5. ožujka 1606.) ${ }^{19}$

4. Popis miraza Katarine, kćeri pok. Jurja Barkovića (24. travnja 1615.). ${ }^{20}$

U fondu HR-DAPA-11 Feudalna jurisdikcija Završje ${ }^{21}$ sačuvane su četiri oporuke pisane glagoljskim pismom i nastale su u razdoblju od 1607. do 1613. godine:

1. Oporuka Fumije Piškovice (5. listopada 1607.),

Acta kancelarije Završje, sig. 37-A-78, f. 184r i 261v²2

2. Oporuka Matije Petrečić iz Kostanjice (5. rujna 1607.),

Acta kancelarije Završje, sig. 37-A-78, f. 187r i f. $260 \mathrm{v}^{23}$

3. Oporuka Gržuna Pučera iz Kostanjice (3. lipnja 1612.),

Acta kancelarije Završje, sig. 37-A-77, f. 81rv²4

4. Oporuka Šimona Pajera iz Kostanjice (18. kolovoza 1613.),

Acta kancelarije Završje, sig. 37-A-77, f. 85r. ${ }^{25}$

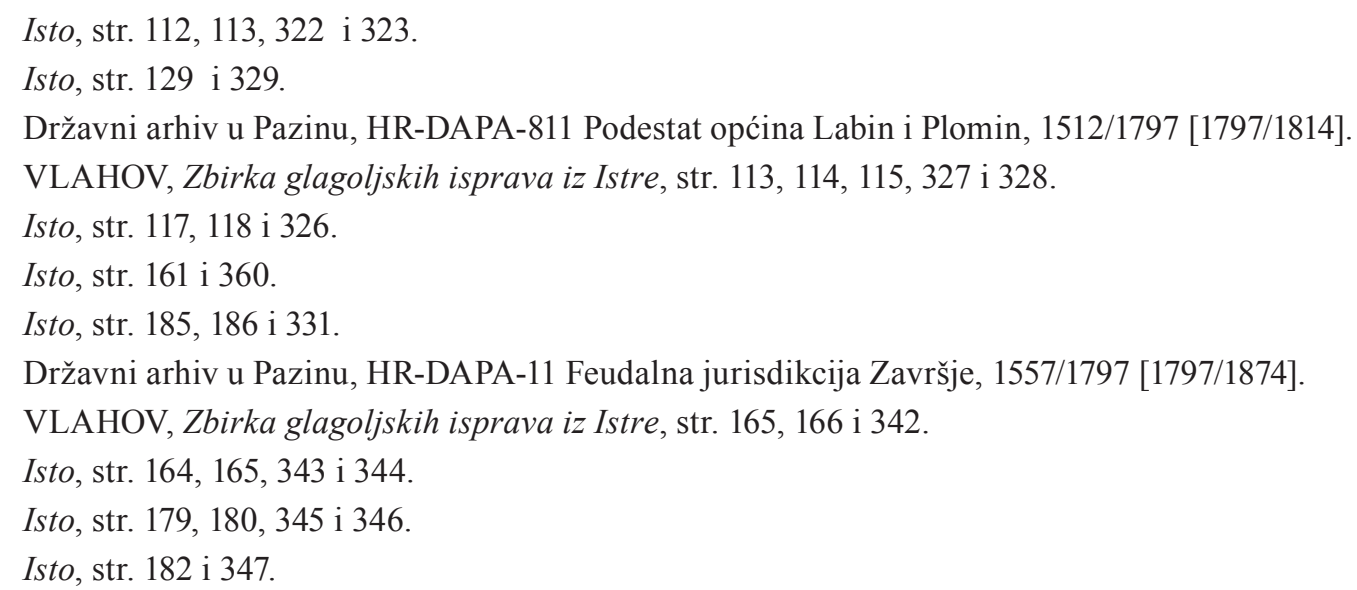


U fondu HR-DAPA-531 Bilježnici Pule ${ }^{26}$ sačuvane su dvije oporuke pisane glagoljskim pismom. Jedna je iz 1791., a druga iz 1800. godine:

1. Oporuka Ive Kužinića (17. prosinca 1791.),

bilježnik: Tiziano Vareton, kut. $28^{27}$

2. Oporuka Vida Fabca iz Pomera (30. studenog 1800.),

bilježnik: Zuanne Razzo, kut. 30. ${ }^{28}$

U fondu HR-DAPA-429 Zbirka matičnih knjiga ${ }^{29}$ čuvaju se dvije matične knjige čiji su zapisi dijelom upisivani glagoljicom:

1. Funtana, 60. Matična knjiga krštenih, 1737. - 1767., kut. 19

2. Sv. Ivan od Šterne, 451. Matična knjiga umrlih 1675. - 1728., krštenih 1717. - 1723., krizmanih 1670. - 1714., kut. 155, a upisi na glagoljici odnose se na Matičnu knjigu krizmanih.

\section{II.}

\section{GLAGOLJSKI DOKUMENT U ŽUPNOM UREDU U BERMU}

Župa sv. Martina u Bermu smještena je $5 \mathrm{~km}$ sjeverozapadno od Pazina. Beramska se župa u pisanim izvorima prema navodima jednoga autora prati već od $1178 .{ }^{30}$ dok prema navodima drugih autora od 1777. godine. ${ }^{31}$ Naselje se prvi put spominje u Buli pape Aleksandra III. Godine 1230. odredbom Fredrika II. Beram je dodijeljen tršćanskom biskupu. ${ }^{32}$ Tršćanski biskup Antun I. Negri 1355. dodjeljuje ga grofu Goričkom. No, istarska grana grofova Goričkih Bermom upravlja tek do 1374., kad su se izumiranjem te grane po muškoj liniji istarskih posjeda domogli Habsburgovci. Beram je otad u sastavu Pazinske grofovije. ${ }^{33}$ Godine 1508. nakratko biva pod vlašću Mlečana.

Sjedište je župe u Bermu dok mjesna nadležnost župe, uz Beram, obuhvaća sljedeća naselja: Belci, Cvitani, Čipri, Kirci, Ladavci, Mala Traba, Šuškali i Vela Traba. ${ }^{34}$

Prilikom organiziranja međunarodne arhivističke konferenciji Stanje i perspektive arhivske glagoljske baštine održane u Pazinu i Rijeci 28. i 29. svibnja 2015. godine, ravnatelj

\footnotetext{
26 Državni arhiv u Pazinu, HR-DAPA-531 Bilježnici Pule, 1626/1797 [1797/1826].

27 VLAHOV, Zbirka glagoljskih isprava iz Istre, str. 225 i 226.

28 Isto, str. 226 i 227.

29 Državni arhiv u Pazinu, HR-DAPA-429 Zbirka matičnih knjiga, 1536/1923.

30 Ivan MILOTIĆ, Crkva u Istri povijesna i kulturna baština, Porečka i Pulska biskupija, Pazin - Poreč, 2010., str. 37.

31 Marijan BARTOLIĆ - Ivan GRAH, Crkva u Istri, III. izdanje, IKD »Juraj Dobrila«, Pazin, 1999., str. 53.

32 MILOTIĆ, Crkva u Istri povijesna i kulturna baština, str. 37.

33 Na ist. mj.

34 Mirela MRAK, Župni ured Beram, sumarni inventar, Državni arhiv u Pazinu, Pazin, 2014., str. 3.
} 
nam je dao zadaću da napišemo nešto o glagoljici. Dogovorile smo se da ćemo uz arhivsko gradivo pisano glagoljicom koje se čuva u Državnom arhivu u Pazinu po prvi put predstaviti javnosti dokument na glagoljici na koji smo naišli 2014. godine prilikom sređivanja arhiva župe Beram, no, u tom trenutku nismo obraćali preveliku pozornost, već smo ga samo primjereno zaštitili, snimili, označili i tehnički pohranili.

Kako smo odnekud trebali započeti, u svemu nam je pomogla dobro poznata činjenica da je Beram bilo priznato istarsko središte glagoljanja, o čemu svjedoče glagoljički zapisi na pergameni, odnosno poznati beramski kodeksi i brevijari koji se čuvaju u Nacionalnoj i sveučilišnoj knjižnici u Ljubljani (koju smo prilikom pisanja ovoga rada i posjetile), zatim dva natpisa na kamenim pločama u župnoj crkvi svetoga Martina iz 1431. i 1493. godine te 127 raznih glagoljskih grafita na zidnim slikama u crkvi sv. Marije na Škriljinama. Na tim je freskama majstor Vincent iz Kastva prikazao život Bogorodičin i Kristov, svetce-zaštitnike, proroke, crkvene oce, vrlo živopisno Poklonstvo triju kraljeva s mnogo narativnih detalja i didaktički sklop tema: Prvi grijeh - Kolo-sreće - Ples mrtvaca - Veronikin rubac s eshataloškim i spasenjskim naglaskom. ${ }^{35}$ Imajući sve to na umu, odlučile smo 2015. godine prilikom organizacije međunarodne arhivističke konferencije Stanje i perspektive hrvatske glagoljske baštine krenuti u transliteraciju i analizu gore spomenutoga pronađenog glagoljskog dokumenta.

Prema obliku dokumenta te načinu upisa odmah smo utvrdile da je riječ o matici. Najprije smo mislile da se radi o matici župe Beram, međutim, zaintrigirao nas je pečat na samom dokumentu iz kojeg se vidi da je riječ o pečatu župnika Tinjana i Muntrilja iz 1899. godine. No, godine s pečata i ime župnika nisu odgovarali upisima iz pronađenoga dokumenta.

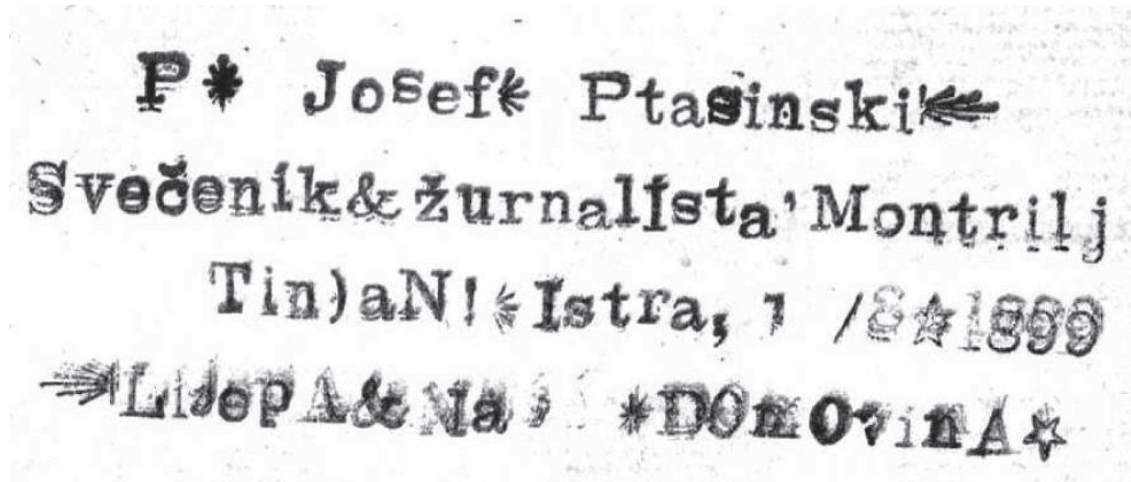

Slika 1. Pečat s upisa

To nas je navelo na trag da je ipak možda riječ o upisima iz Muntrilja. Pregledom dostupnih matica Župnoga ureda Muntrilj, sa sigurnošću smo utvrdile da je riječ o župniku koji je tada župnikovao u Muntrilju.

35 Branko FUČIĆ, Glagoljski natpisi, Djela JAZU, knj. 57, Jugoslavenska akademija znanosti i umjetnosti, Zagreb, 1982., str. 80. 


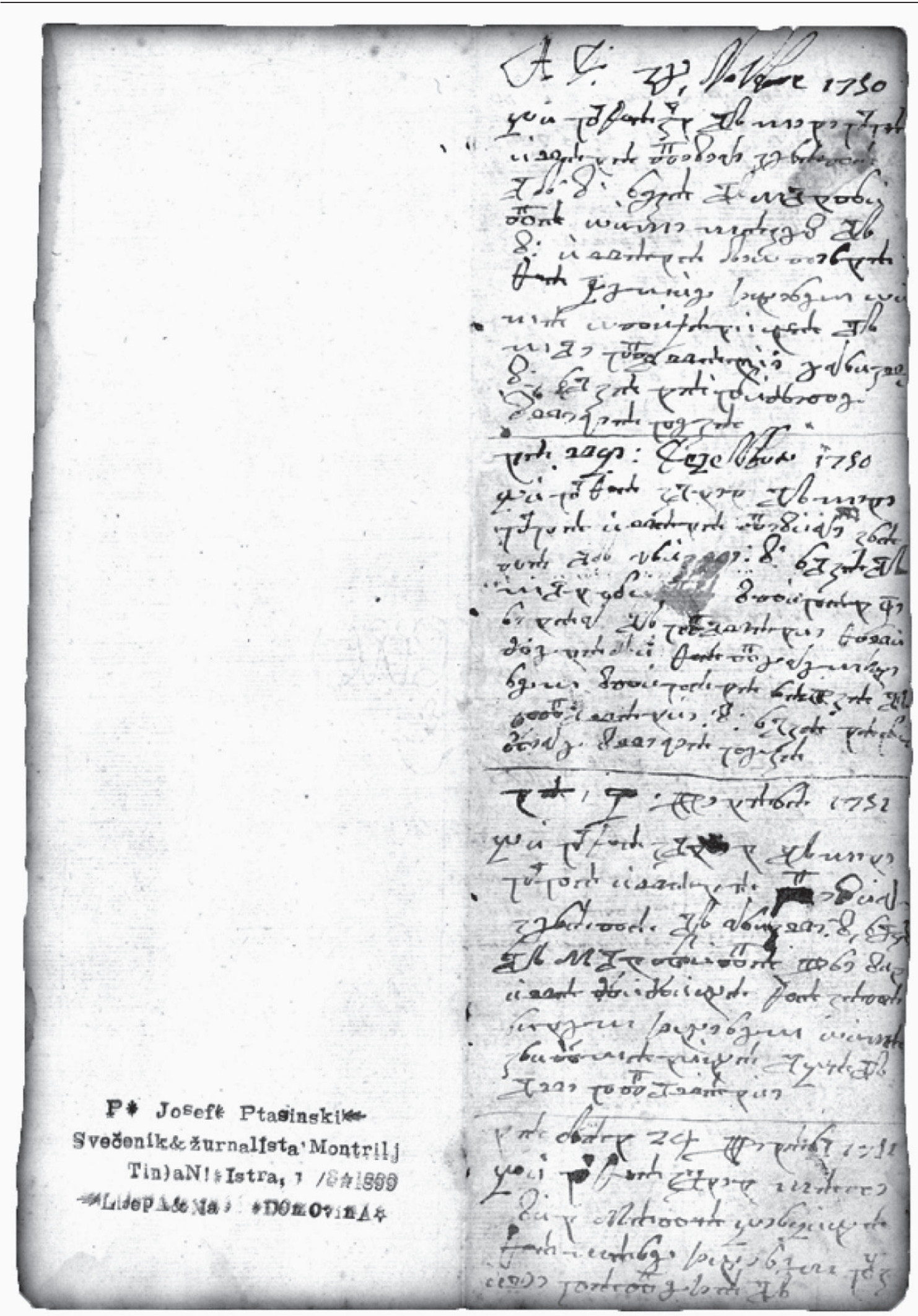

Slika 2. Prva stranica pronađenoga ulomka Matične knjige vjenčanih Muntrilj 1731-1754. 


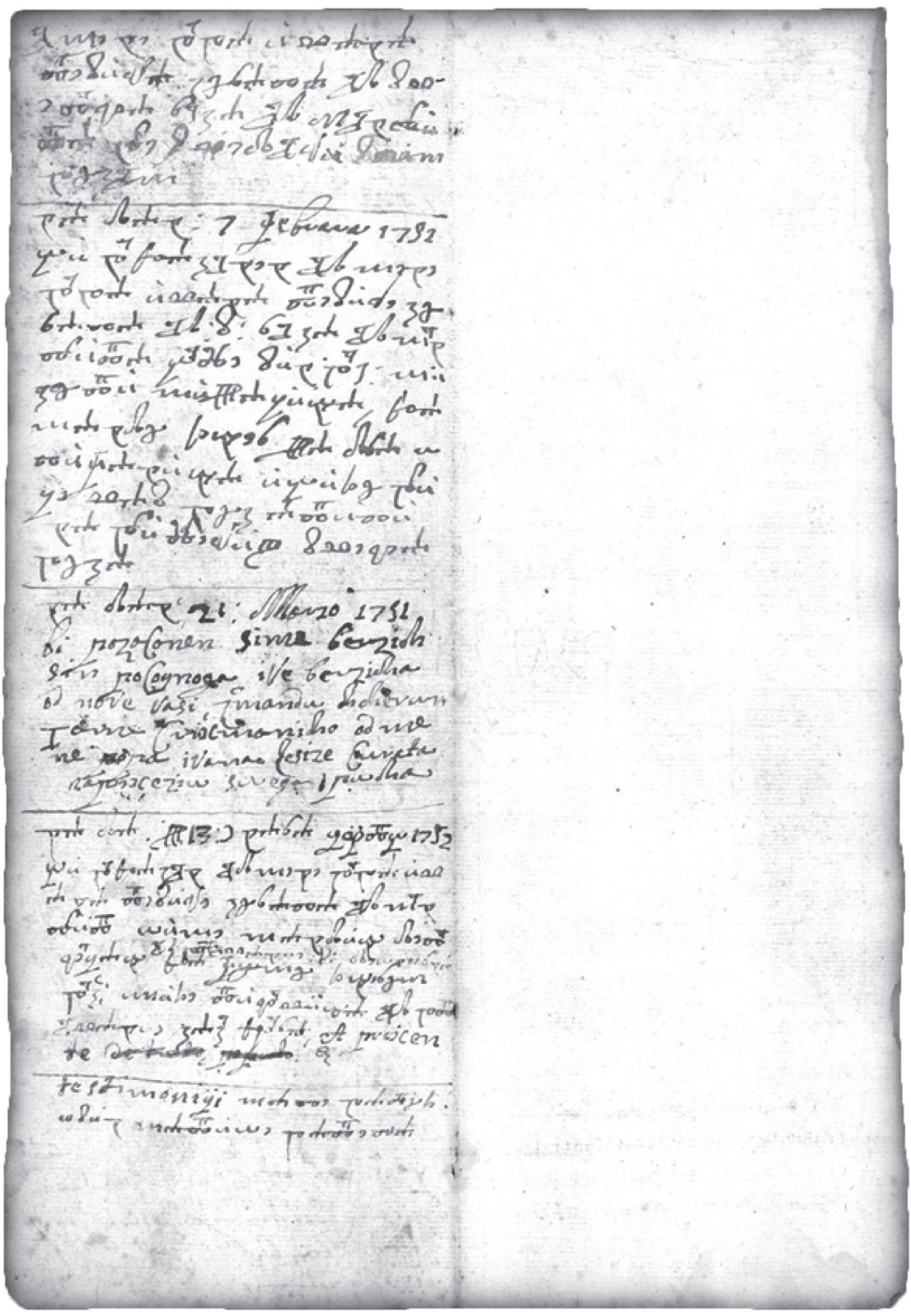

Slika 3. Druga stranica pronađenoga ulomka Matične knjige vjenčanih Muntrilj 1731-1754. 
Kako bismo utvrdile o kojoj je matici riječ, krenule smo u transliteraciju jednoga od zapisa i došle do zaključka da je riječ o Matičnoj knjizi vjenčanih. Radi se o upisu iz 7. veljače 1752. (što je upisano latinicom), a dalje piše:

»Bi pozakonen od mene popa Ivana Lesice kurata od S. Roka od Montrila Bože sin pok. Nikole Miha()ića za Mandu héer Jadra Štifanića i bihu pri()e vas puk a liti na prežeciju svega puka.«

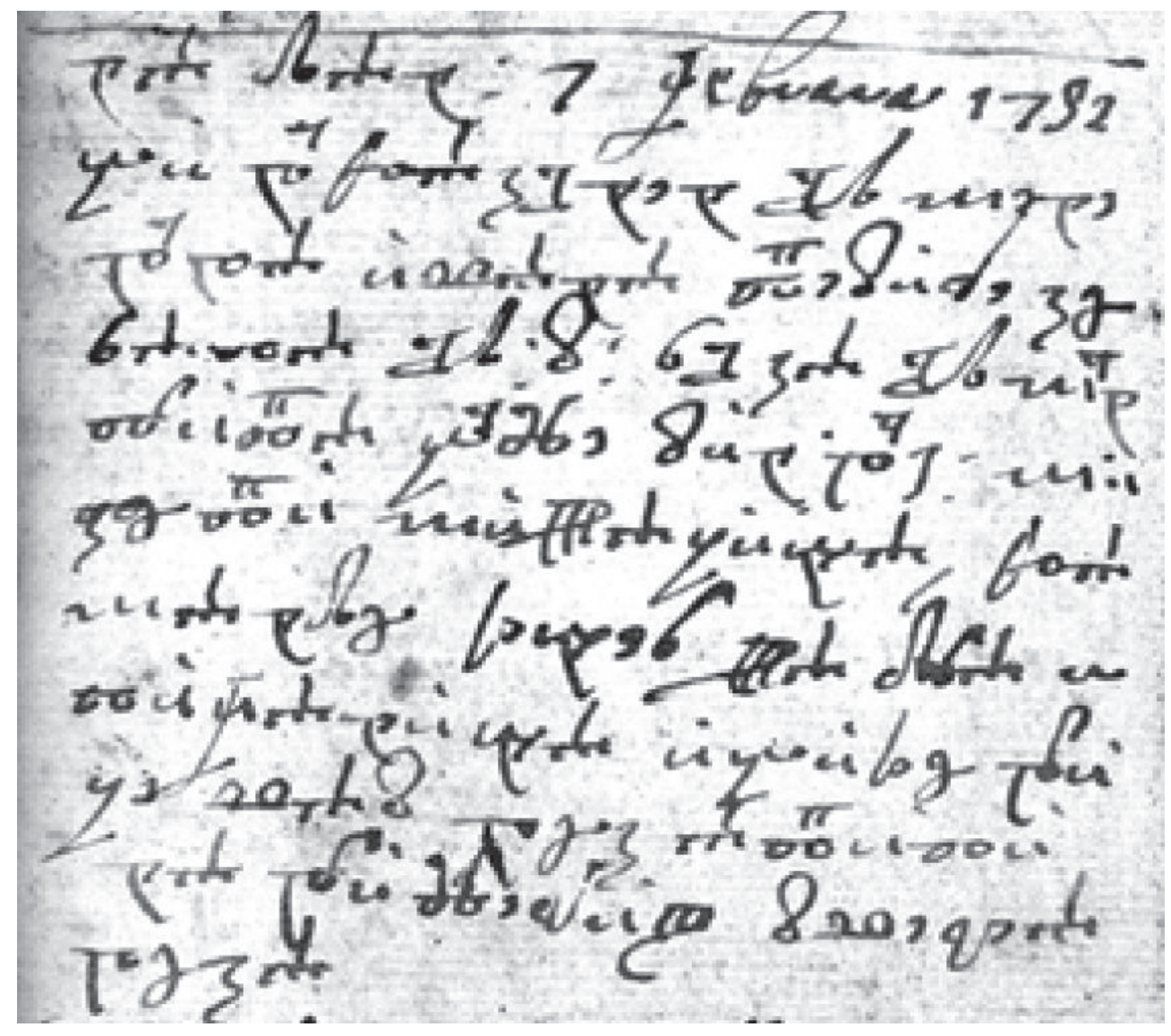

Slika 4. Transliteriran upis

Kao smjernicu za utvrđivanje prostornoga podrijetla matice, proučile smo i upisana prezimena u knjizi (npr. Štifanić, tipično prezime u zaseoku Pinčani koje pripada župi Muntrilj, zatim prezime Žužić itd...) te smo utvrdile da se zaista radi o muntriljskom kraju.

Kako bismo svoje »otkriće« upotpunile i potvrdile, a znajući da se u Arhivu Hrvatske akademije znanosti i umjetnosti čuva šest muntriljskih matica pisanih glagoljicom (Matična knjiga krštenih/rođenih 1731-1754., Matična knjiga krštenih/rođenih 1754-1775., Matična knjiga vjenčanih 1730/1753., Matična knjiga vjenčanih 1754/1811., Matična knjiga umrlih 1731-1743. te Matična knjiga umrlih XVIII. i početak XIX. stoljeća), odlučile smo kontaktirati upravo navedeni Arhiv Hrvatske akademije znanosti i umjetnosti. Već nam je pri prvom kontaktu gospođa Marta Jašo potvrdila da je riječ o istom svećeniku te kako 
upravo za te godine više nema upisa na glagoljici, već na latinici, odnosno da su upisi na glagoljici do 1744. godine. Nakon nekoliko kontaktiranja i konzultacija dobile smo od gospođe Marte Jašo potvrdu da je definitivno riječ o odlomku iz Matične knjige vjenčanih Muntrilj 1731-1754., koja se čuva u Arhivu HAZU-a, a koji nedostaje upravo za godine koje smo mi pronašle. Riječ je o šest upisa vjenčanih: dva se upisa odnose na 1750., a ostala četiri na 1752. godinu.

Kako i zašto su se ovi glagoljski upisi našli među arhivskim gradivom Župnoga ureda Beram, još se mora istražiti. Zanimljivo je napomenuti da u čitavom arhivskom gradivu Župnoga ureda Beram, koji datira od 1687. godine i koji se sastoji od triju serija: Uprava nad župom, Župne evidencije i Računovodstvo, a unutar serija nailazimo na podserije poput: urudžbenih zapisnika, župnih spisa, spisa osobite važnosti, ženidbenih spisa, računskih spisa, matica krštenih, vjenčanih i umrlih, knjiga stanja duša, evidencija krizmanih te računskih knjiga, nisu pronađeni drugi upisi na glagoljici, osim ovoga koji je, po svemu sudeći, nastao u Muntrilju, a ne u Bermu. Odlomak se pronađene matice danas čuva u gradivu Župnoga ureda Beram.

\section{III.}

\section{KIRČEVE »MRVICE«}

Dr. Marica Čunčić je, prilikom održavanja javnog predavanja u Državnom arhivu u Pazinu na temu Glagoljica u Istri, zaključila kako je iznimno važno evidentirati i popisati pronalazak svakoga glagoljskog upisa. Stoga ćemo ovaj rad zaključiti riječima Luke Kirca koji u knjizi Crtice iz istarske povijesti piše sljedeće: »A da se glagoljica kroz vjekove uz tolike neprijatelje sačuvala, znak je, da je bila gusto posijana na plodovito tlo i gojena od vjerne djece do mučeništva« te »... ako dalje uzmemo u obzir, da su glagoljski spisi nestajali također radi nepoznavanja, omalovažavanja i mržnje, onda nije čudo, što nam u dokaz negda cvatuće glagoljice u Istri ostaše samo mrvice. Dužnost je svakog rodoljuba da i takove mrvice sakuplja i bilježi«. ${ }^{36}$

36 Luka KIRAC, Crtice iz istarske povijesti, Nakladni zavod Hrvatske, Zagreb, 1946., str. 217 i 232. 


\section{SAŽETAK \\ Prilog istarskoj arhivskoj glagoljskoj baštini (glagoljica u \\ Državnom arhivu u Pazinu i u Župnom uredu u Bermu)}

Rad se prvenstveno temelji na novootkrivenoj mrvici glagoljske pisane baštine središnje Istre - fragmentu glagoljskoga zapisa iz muntriljske Matične knjige vjenčanih, pronađenom 2014. godine tijekom sređivanja arhivskoga gradiva Župnoga ureda u Bermu. U prvom se dijelu rada pruža sažet pregled glagoljskoga gradiva pohranjenoga u Državnom arhivu u Pazinu kako bi se stekao uvid u širinu i bogatstvo sačuvanoga glagoljskog gradiva. U drugom dijelu rada autorice iznose svojevrsno izvješće arhivskoga rada na terenu, odnosno rad na samoj transliteraciji pronađenoga fragmenta.

\section{SUMMARY}

\section{A Contribution to the Istrian Archival Glagolitic Heritage (The Glagolitic Alphabet at the State Archives in Pazin and the Parish Office of Beram)}

This paper is primarily based on the newly discovered particle of the Glagolitic written heritage of central Istria - a fragment of the Glagolitic record from the Register of Marriages of Muntrilj, found in 2014 during the arrangement of the archives of the Parish Office of Beram. The first part of the paper provides a concise overview of the Glagolitic documents held in the State Archives in Pazin to give insight into the breadth and richness of the preserved Glagolitic material. In the second part the authors report on their archival fieldwork as well as on the transliteration of the found fragment.

\section{RIASSUNTO}

Il contributo al patrimonio archivistico istriano in glagolitico (il glagolitico presente nell'Archivio di Stato di Pisino e nell'Ufficio parrocchiale di Beram (Vermo))

Il testo si basa in primo luogo sulla scoperta recente di una briciola del patrimonio scritto in glagolitico dell'Istria centrale - frammento di un'annotazione in glagolitico dal Registro dei matrimoni di Muntrilj (Montreo), scoperto nel 2014 durante la sistematizzazione del materiale archivistico dell'Ufficio parrocchiale di Vermo. Nella prima parte del testo si offre una rassegna sintetica del materiale glagolitico conservato presso l'Archivio di Stato di Pisino per poter osservare l'ampiezza e la ricchezza del materiale in glagolitico conservato. Nella seconda parte le autrici riportano un tipo di rapporto relativo al lavoro archivistico sul terreno ovvero il lavoro di trasliterazione del frammento trovato. 